\title{
Development of a program for toric intraocular lens calculation considering posterior corneal astigmatism, incision- induced posterior corneal astigmatism, and effective lens position
}

\section{Youngsub Eom}

Dongok Ryu ${ }^{2}$

Dae Wook Kim ${ }^{3}$

Seul Ki Yang ${ }^{2}$

Jong Suk Song

Sug-Whan Kim $^{3}$

Hyo Myung Kim 1,4,*

Phone 82-2-920-5776

Email hyomkim@kumc.or.kr

1 Department of Ophthalmology, Korea University College of Medicine, Seoul, South Korea

2Center for Galaxy Evolution Research, Yonsei University, Seoul, South Korea, Yonsei University Observatory, Yonsei University, Seoul, South Korea, and Space Optics Laboratory, Department of Astronomy, Yonsei University, Seoul, South Korea

3 College of Optical Sciences, University of Arizona, Tucson, AZ, USA

4 Department of Ophthalmology, Anam Hospital, Korea University College of Medicine, 126-1, Anam-dong 5-ga, Seongbuk-gu, Seoul, 136-705 South Korea

\section{Abstract}

\section{Background}

To evaluate the toric intraocular lens (IOL) calculation considering posterior 
corneal astigmatism, incision-induced posterior corneal astigmatism, and effective lens position (ELP).

\section{Methods}

Two thousand samples of corneal parameters with keratometric astigmatism $\geq$ $1.0 \mathrm{D}$ were obtained using bootstrap methods. The probability distributions for incision-induced keratometric and posterior corneal astigmatisms, as well as ELP were estimated from the literature review. The predicted residual astigmatism error using method $\mathrm{D}$ with an IOL add power calculator (IAPC) was compared with those derived using methods A, B, and C through MonteCarlo simulation. Method A considered the keratometric astigmatism and incision-induced keratometric astigmatism, method B considered posterior corneal astigmatism in addition to the $\mathrm{A}$ method, method $\mathrm{C}$ considered incision-induced posterior corneal astigmatism in addition to the $\mathrm{B}$ method, and method D considered ELP in addition to the C method. To verify the IAPC used in this study, the predicted toric IOL cylinder power and its axis using the IAPC were compared with ray-tracing simulation results.

\section{Results}

The median magnitude of the predicted residual astigmatism error using method D (0.25 diopters [D]) was smaller than that derived using methods $\mathrm{A}$ $(0.42 \mathrm{D}), \mathrm{B}(0.38 \mathrm{D})$, and $\mathrm{C}(0.28 \mathrm{D})$ respectively. Linear regression analysis indicated that the predicted toric IOL cylinder power and its axis had excellent goodness-of-fit between the IAPC and ray-tracing simulation.

\section{Conclusions}

The IAPC is a simple but accurate method for predicting the toric IOL cylinder power and its axis considering posterior corneal astigmatism, incision-induced posterior corneal astigmatism, and ELP.

\section{Keywords}

Toric intraocular lens

Posterior corneal astigmatism, Incision-induced astigmatism

Effective lens position

This work was presented in part at XXXIII Congress of the European Society of Cataract \& Refractive Surgeons (ESCRS), Barcelona, Spain, 2015. 
The online version of this article (doi: 10.1007/s00417-016-3446-3 ) contains supplementary material, which is available to authorized users.

\section{Introduction}

Toric intraocular lenses (IOLs) reduce corneal astigmatism, resulting in improved uncorrected distance visual acuity and increased spectacle independence [1]. It is important to select ideal candidates and to precisely predict the corneal plane effective cylinder power of toric IOLs [2, 3]. Many previous studies have studied rotational stability as a way to evaluate the outcomes of toric IOLs [4, 5]. However, in addition to toric IOL rotation, there are various factors that affect corneal astigmatism correction by toric IOL [6]. Recent studies have shown the effect of posterior corneal astigmatism on corneal astigmatism correction by toric IOLs [7, 8]. Nemeth et al. [9] demonstrated that the occurrence of incision-induced posterior corneal astigmatism is not negligible, although the amount of incision-induced posterior corneal astigmatism was smaller than that of incision-induced keratometric astigmatism. The corneal plane effective cylinder power of toric IOLs was shown to be affected by the effective lens position (ELP) $[10,11]$.

Although surgeons are aware of the factors related to toric IOL calculations, such as posterior corneal astigmatism, incision-induced corneal astigmatism, and ELP, predicting corneal astigmatism correction by toric IOLs considering all of these factors is still a difficult task. This study introduces and evaluates the accuracy of an IOL add power calculator (IAPC) that predicts the corneal astigmatism correction by toric IOLs based on the anterior and posterior corneal radii, incision-induced keratometric and posterior corneal astigmatisms, and ELP.

\section{Materials and methods}

\section{Study population}

This retrospective study included 376 eyes from 376 subjects who underwent measurements using a single Scheimpflug camera (Pentacam; Oculus Optikgeräte $\mathrm{GmbH}$, Wetzlar, Germany) for bootstrap sampling. Retrospective reviews were performed on all subjects who underwent a single Scheimpflug camera examination at our institution between May 1, 2009 and January 31, 2015. In total, 928 healthy eyes from 928 subjects 30 years of age or older were selected according to the method described in detail in our previous study [12]. Of 928 eyes, 376 with keratometric astigmatism $\geq 1.0 \mathrm{D}$ were used in the 
bootstrap sampling. This study was approved by the Institutional Review Board of Korea University Ansan Hospital, Gyeonggi, Korea. All research and data collection adhered to the tenets of the Declaration of Helsinki.

\section{Bootstraping}

From the dataset of 376 eyes analyzed with a single Scheimpflug camera, this study took 2,000 bootstrap samples with corneal parameters of keratometric and posterior corneal power, keratometric and posterior corneal cylinder power, anterior and posterior corneal flat meridian, and central corneal thickness. To obtain bootstrap samples, the INDEX() and RAND() functions in Excel (Microsoft Inc., Redmond, WA, USA) were used. The results of the bootstrap sampling were then used to calculate the predicted residual astigmatism during Monte-Carlo simulation.

\section{Monte-Carlo simulation}

In Monte-Carlo simulation, the random variables used were incision-induced keratometric and posterior corneal astigmatisms, as well as ELP. The mean and $\mathrm{SD}$ values were used to generate random variables. Mean $( \pm \mathrm{SD})$ incisioninduced keratometric and posterior corneal astigmatisms were $0.49 \pm 0.29 \mathrm{D}$ and $0.32 \pm 0.29 \mathrm{D}$, rspectively [9]; and mean ELP was $4.97 \pm 0.38 \mathrm{~mm}$ [3]. It was assumed that the corneal incision was an on-axis clear corneal incision that centered on the steepest corneal meridian. To generate random variables with a normal distribution, the RAND() and NORMINV functions in Excel (Microsoft Inc.) were used. A total of 2,000 probability distributions, each with a random set of incision-induced keratometric and posterior corneal astigmatism values and ELP, were generated and matched at a ratio of 1:1 to 2,000 bootstrap samples, each with a set of corneal parameters of keratometric and posterior corneal power, keratometric and posterior corneal cylinder power, anterior and posterior corneal flat meridian, and central corneal thickness. The predicted residual astigmatism of 2,000 bootstrap samples was calculated using a MonteCarlo simulation.

\section{Main outcome measure(s)}

Predicted residual astigmatism

Predicted residual astigmatism was defined as the vectorial difference between corneal astigmatism and the predicted corneal plane toric IOL astigmatism [13-15]. Calculations of the predicted residual astigmatism were completed using five methods, as follows:

Method used keratometric astigmatism and an intended incision-induced 
A keratometric astigmatism of $0.49 \mathrm{D}$.

Method used total corneal astigmatism (see below) and the intended incisionB induced keratometric astigmatism of $0.49 \mathrm{D}$.

Method used total corneal astigmatism and the intended incision-induced

C keratometric and posterior corneal astigmatisms $(0.49 \mathrm{D}$ and $0.32 \mathrm{D}$ respectively).

Method used total corneal astigmatism, the intended incision-induced

D keratometric and posterior corneal astigmatisms $(0.49 \mathrm{D}$ and $0.32 \mathrm{D}$ respectively), and ELP.

Method used total corneal astigmatism and the generated variables of E incision-induced keratometric and posterior corneal astigmatisms and ELP. The residual astigmatism calculated by this method was thought to be the actual residual astigmatism.

In the calculation of toric IOL, it was assumed that the anterior cylinder axis marks on the toric IOLs were accurately placed at the steep meridian of total corneal astigmatism.

\section{Total corneal astigmatism}

\section{AQ1}

Total corneal astigmatism was defined as the vectorial sum of the anterior corneal astigmatism and the anterior corneal plane value of the posterior corneal astigmatism [13-15]. To consider the incision-induced keratometric astigmatism, the vector components of incision-induced keratometric astigmatism were added to keratometric astigmatism using vector addition. When considering the incision-induced posterior corneal astigmatism (methods $\mathrm{C}, \mathrm{D}$, and $\mathrm{E}$ ), the vector components of incision-induced posterior corneal astigmatism were added to the posterior corneal astigmatism using vector addition.

The vergence equation was used to calculate the anterior corneal plane value of the posterior corneal astigmatism as follows [16]:

$$
\begin{aligned}
K_{\text {Ant_Steep_Post }} & =\frac{1}{\frac{1}{K_{\text {Steep_Post }}}+\frac{T}{n_{\text {Cornea }} \times 1000}} \\
K_{\text {Ant_Flat_Post }} & =\frac{1}{\frac{1}{K_{\text {Flat_Post }}}+\frac{T}{n_{\text {Cornea }} \times 1000}}
\end{aligned}
$$




$$
M_{\text {Ant_Post }}=K_{\text {Ant_Steep_Post }}-K_{\text {Ant_Flat_Post }}
$$

where $K_{\text {Ant_Steep_Post }}$ is the anterior corneal plane value of the steep posterior corneal power, $\bar{K}_{\text {Steep_Post }}$ is the steep posterior corneal power, $T$ is the central corneal thickness, $n_{\text {Cornea }}$ is the refractive index of the corneal tissue (1.376), $K_{\text {Ant_Flat_Post }}$ is the anterior corneal plane value of the flat posterior corneal power, $\bar{K}_{\text {Flat Post }}$ is the flat posterior corneal power, and $M_{\text {Ant Post }}$ is the magnitude of the anterior corneal plane value of the posterior corneal cylinder power.

Corneal plane effective cylinder power of toric intraocular lens When the ELP was not considered in the toric IOL calculation, the corneal plane effective cylinder power of the toric IOL was estimated using a fixed ratio of 1.46 [17]. On the other hand, when considering ELP, the refractive vergence formula was used to calculate the predicted corneal plane effective cylinder power of the toric IOL using K and ELP as follows [11, 18, 19]:

$$
D_{\text {Cornea }}=\frac{1336}{\frac{1336}{\frac{1336}{\frac{1336}{K_{0}}-E L P}+D_{I O L}}+E L P}-K_{0},
$$

where $D_{\text {Cornea }}$ is the corneal plane effective cylinder power of the toric IOL, $K_{0}$ is the net corneal power, $E L P$ is the effective lens position, and $D_{I O L}$ is the IOL plane toric IOL cylinder power. For $K_{0}$, the net optical corneal power was obtained by multiplication of the keratometric power using a refractive index of 1.3375 and 0.98765431 , or the total corneal power was used [19].

Total corneal power was calculated using a thick lens formula based on corneal thickness, anterior corneal radius, and posterior corneal radius [16].

\section{Predicted residual astigmatism error}

The predicted residual astigmatism error was defined as the vectorial difference between the predicted residual astigmatism derived using methods $\mathrm{A}$ to $\mathrm{D}$ and the actual residual astigmatism derived using method $\mathrm{E}$. The median magnitude of the predicted residual astigmatism error using method $\mathrm{D}$ was compared with those estimated using methods A to C.

\section{IOL add power calculator}

Excel was used to develop the IAPC (Supplemental material, available at http://link.springer.com/journal/417 ). The calculator determines the corneal 
plane toric IOL cylinder power and the spectacle plane multifocal IOL add power based on the ELP calculated with the Haigis [20 ], Hoffer Q [21, 22], and SRK/T [23, 24] formulae. It also provides a calculated total corneal astigmatism and a predicted residual astigmatism from the anterior and posterior corneal radii, incision-induced keratometric and posterior corneal astigmatisms, and ELP (Fig. 1). Our recent study demonstrated that the predicted spectacle plane multifocal IOL add power based on ELP is more accurate than the value presented by the manufacturer [25].

\section{Fig. 1}

The intraocular lens add power calculator used in this study

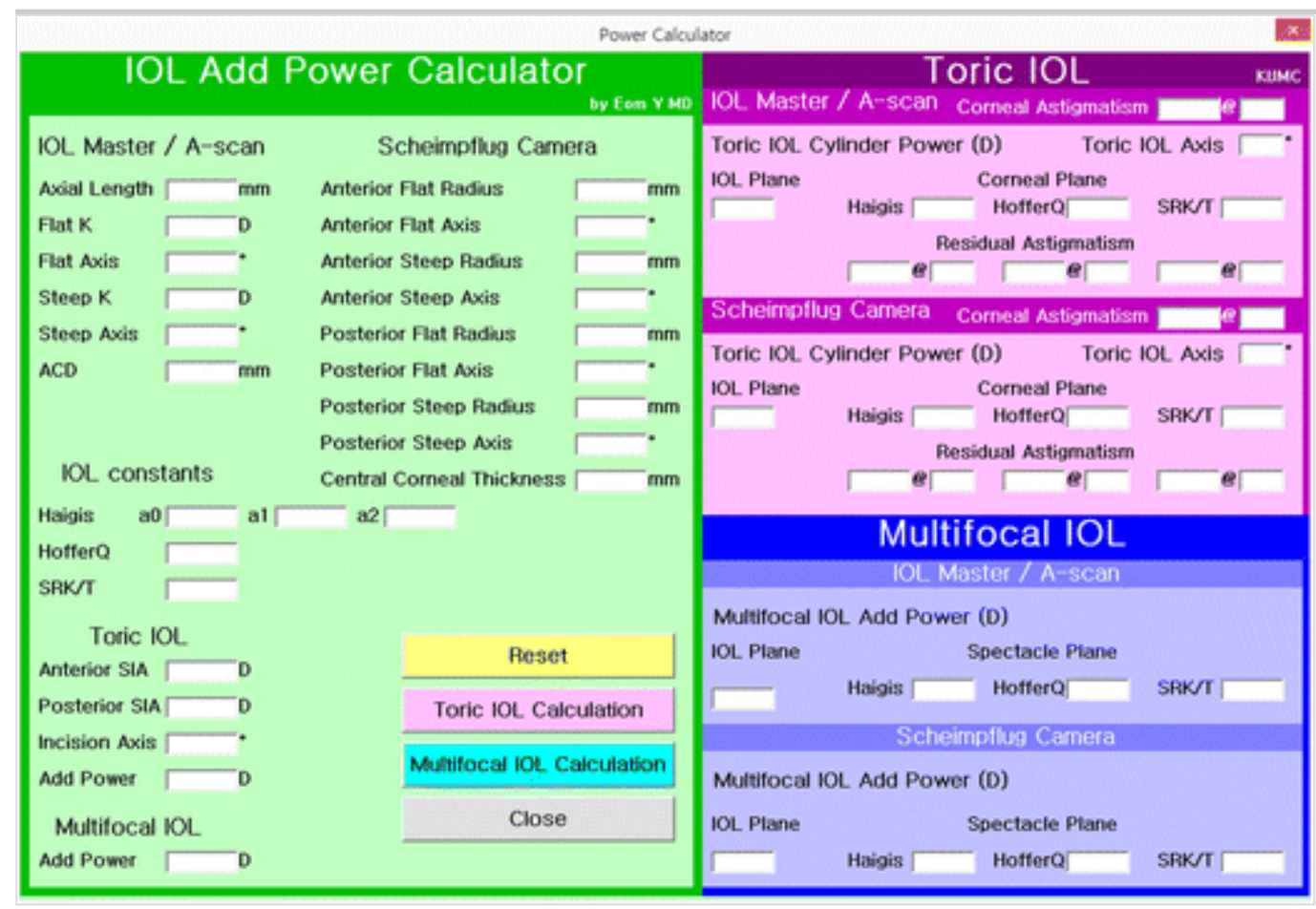

\section{Investigation of the IOL add power calculator for calculating the toric IOL cylinder power and its axis}

Zemax optical design software (Radiant Zemax, LLC, Redmond, WA, USA) was used to model a three-dimensional pseudophakic human eye with a toric IOL based on the Arizona eye model (Table 1) [26, 27]. The analytical solution (method E using the IAPC with subsequent mathematical calculation to obtain the IOL plane toric IOL cylinder power and its axis to fully correct the total corneal astigmatism) of the predicted toric IOL cylinder power and its axis was compared to and confirmed with the independently calculated results from raytracing simulation using Zemax software. In order to obtain the IOL plane toric IOL cylinder power and its axis to fully correct the total corneal astigmatism using ray-tracing simulation, optimization (targeting a minimum retinal spot radius root-mean-square) was performed after the toric IOL cylinder power and 
its axis were set as variables while the other parameters were fixed at nominal values. Values of keratometric astigmatism (range, 1.00-6.00 CD), posterior corneal astigmatism (range, $0.10-1.00 \mathrm{CD}$ ), steep meridian difference between the anterior and posterior corneal surfaces (range, 0-90 degrees), central corneal thickness (range, 0.40-0.60 mm), and ELP (range, 4.00-6.00 mm) were included in this study. These parameters were used to consider and evaluate various cases using the IAPC and ray-tracing simulation.

\section{Table 1}

Nominal values used in this study's model of a pseudophakic eye with a toric intraocular lens

\begin{tabular}{|c|c|c|c|c|}
\hline Surface & $\begin{array}{l}\text { Radius } \\
(\mathbf{m m})\end{array}$ & $\begin{array}{l}\text { Thickness } \\
\text { (mm) }\end{array}$ & $\begin{array}{c}\text { Conic } \\
\text { constant }\end{array}$ & $\begin{array}{l}\text { Refractive index }(\lambda= \\
\qquad 555 \mathrm{~nm})\end{array}$ \\
\hline \multicolumn{2}{|c|}{ Anterior cornea } & $0.400-0.600$ & -0.25 & 1.376 \\
\hline $\begin{array}{c}\text { Flat } \\
\text { surface }\end{array}$ & $\begin{array}{l}7.849- \\
8.333\end{array}$ & & & \\
\hline $\begin{array}{l}\text { Steep } \\
\text { surface }\end{array}$ & $\begin{array}{l}7.258- \\
7.670\end{array}$ & & & \\
\hline \multicolumn{2}{|c|}{ Posterior cornea } & $3.000-5.000$ & -0.25 & 1.336 \\
\hline $\begin{array}{c}\text { Flat } \\
\text { surface }\end{array}$ & $\begin{array}{l}6.553- \\
7.075\end{array}$ & & & \\
\hline $\begin{array}{l}\text { Steep } \\
\text { surface }\end{array}$ & $\begin{array}{l}6.012- \\
6.448\end{array}$ & & & \\
\hline Pupil & 0 & 1.000 & & 1.336 \\
\hline \multicolumn{2}{|c|}{ Anterior IOL } & 0.750 & 0.00 & 1.470 \\
\hline $\begin{array}{c}\text { Flat } \\
\text { surface }\end{array}$ & $\begin{array}{l}35.589- \\
75.967\end{array}$ & & & \\
\hline $\begin{array}{l}\text { Steep } \\
\text { surface }\end{array}$ & $\begin{array}{l}25.297- \\
46.613\end{array}$ & & & \\
\hline $\begin{array}{l}\text { Posterior } \\
\text { IOL }\end{array}$ & -15.723 & 18.000 & 0.00 & 1.336 \\
\hline Retina & -13.500 & 0.000 & 0.00 & \\
\hline
\end{tabular}

\section{Statistical analysis}

Descriptive statistics for all patient data and data from theoretical predictions were obtained using the Statistical Package for Social Sciences version 12.0 (SPSS Inc., Chicago, IL, USA). A Friedman test was performed to compare the 
median magnitude of the predicted residual astigmatism error among the four methods (A, B, C, and D). Linear regression analyses to evaluate the goodnessof-fit between the predicted toric IOL cylinder power and its axis needed to fully correct corneal astigmatism by the IAPC and those by ray-tracing simulation were performed. Agreement between the IAPC and ray-tracing simulation was also analyzed using a Bland-Altman plot.

\section{Results}

The mean $( \pm \mathrm{SD})$ keratometric cylinder power was $1.63 \pm 0.71 \mathrm{D}$ (range, 1.00 $5.57 \mathrm{D}$ ), and the mean posterior corneal astigmatismcylinder power was $0.42 \pm$ $0.20 \mathrm{D}$ (range, $0.01-1.33 \mathrm{D}$ ). The anterior corneal flat meridian was horizontally aligned ( $180 \pm 30$ degrees) in $75.9 \%$ and vertically aligned ( $90 \pm 30$ degrees) in $16.7 \%$ of bootstrap samples. The posterior corneal flat meridian was horizontally aligned in $94.5 \%$ and vertically aligned in $2.4 \%$ of bootstrap samples. Other parameters, including keratometric corneal power, posterior corneal power, and central corneal thickness, are shown in Fig. 2 and Table 2. Probability distributions for incision-induced keratometric and posterior corneal astigmatisms and ELP are shown in Table 2.

Fig. 2

Distribution of corneal parameters resulting from bootstrap sampling. a Keratometric corneal power. b Keratometric cylinder power. c Anterior corneal flat meridian. d Posterior corneal power. e Posterior corneal cylinder power. f Posterior corneal flat meridian. g Central corneal thickness 

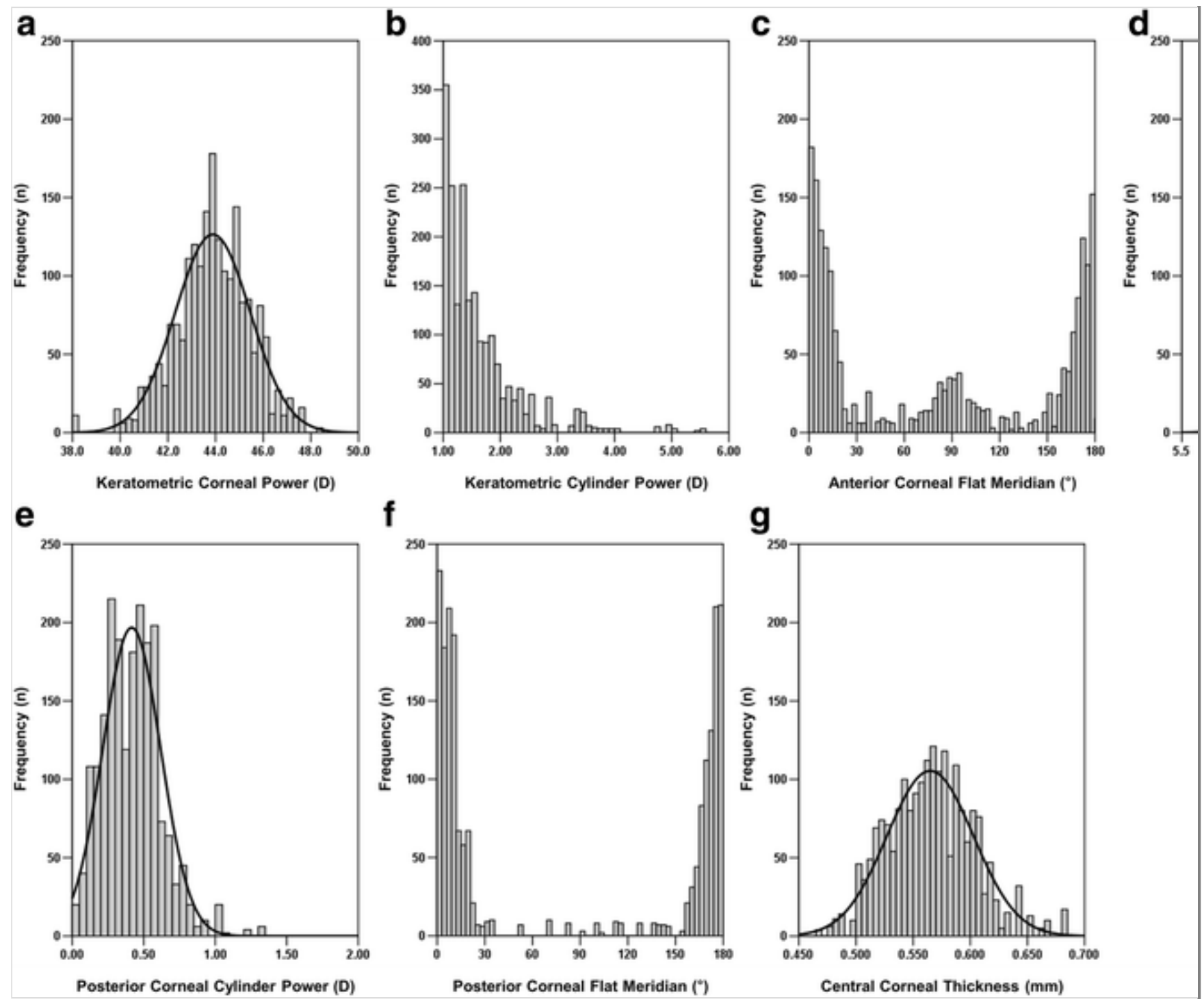

\section{Table 2}

Biometries of bootstrap samples, and the probability distributions of incision-induced keratometric and posterior corneal astigmatisms and effective lens position in a study of toric intraocular lens calculation $(n=2,000)$

\begin{tabular}{|l|l|l|}
\hline \multicolumn{1}{|c|}{ Parameter } & \multicolumn{1}{|c|}{ Mean (SD) } & \multicolumn{1}{c|}{ Range } \\
\hline Keratometric corneal power, D & $43.88(1.58)$ & $38.15-48.32$ \\
\hline Keratometric cylinder power, D & $1.63(0.71)$ & $1.00-5.57$ \\
\hline Anterior corneal flat meridian, Degrees & $83(72)$ & $0-180$ \\
\hline Posterior corneal power, D & $6.44(0.24)$ & $5.78-7.13$ \\
\hline Posterior corneal cylinder power, D & $0.42(0.20)$ & $0.01-1.33$ \\
\hline Posterior corneal flat meridian, Degrees & $83(80)$ & $0-180$ \\
\hline Central corneal thickness, mm & $0.565(0.038)$ & $0.465-0.682$ \\
\hline Incision-induced keratometric astigmatism, D & $0.51(0.27)$ & $0.00-1.50$ \\
\hline Incision-induced posterior corneal astigmatism, D & $0.33(0.23)$ & $0.00-1.26$ \\
\hline
\end{tabular}


$\mathrm{SD}=$ standard deviation; $\mathrm{D}=$ diopters $; \mathrm{IOL}=$ intraocular lens

* The eylinder power of the toric IOL at the IOL plane

The median magnitude of the predicted residual astigmatism error (interquartile range) derived using method $\mathrm{D}(0.25 \mathrm{D}[0.12-0.43 \mathrm{D}])$ was smaller than that predicted using methods A, B, or C (0.42 D [0.26-0.66 D], $0.38 \mathrm{D}$ [0.17-0.62 $\mathrm{D}]$, and $0.28 \mathrm{D}$ [0.14-0.48 D] respectively; Table 3 ). The percentages of eyes that achieved a magnitude of predicted residual astigmatism error within 0.25 , 0.50 , and $0.75 \mathrm{D}$ of the predicted residual astigmatism determined using methods $\mathrm{A}, \mathrm{B}$, and $\mathrm{C}$ were $24.3 \%, 59.3 \%$, and $81.3 \%$ respectively with method A; $35.0 \%, 64.8 \%$, and $83.3 \%$ respectively with method $\mathrm{B}$; and $46.6 \%, 78.3 \%$, and $93.7 \%$ respectively with method $\mathrm{C}$. These percentages improved to $50.8 \%$, $82.8 \%$, and $96.4 \%$ respectively when the residual astigmatism was predicted using method D (Table 3 ).

\section{Table 3}

The median magnitude of the predicted residual astigmatism error calculated using four methods in a study of toric intraocular lens calculation $(n=2,000)$

\begin{tabular}{|l|l|l|l|l|}
\hline & \multicolumn{1}{|c|}{ Method A } & \multicolumn{1}{|c|}{ Method B } & \multicolumn{1}{|c|}{ Method C } & \multicolumn{1}{|c|}{ Method D } \\
\hline $\begin{array}{l}\text { Magnitude of RAE, } \\
\mathrm{D}^{*}\end{array}$ & $\begin{array}{l}0.42(0.26- \\
0.66)\end{array}$ & $\begin{array}{l}0.38(0.17- \\
0.62)\end{array}$ & $\begin{array}{l}0.28(0.14- \\
0.48)\end{array}$ & $\begin{array}{l}0.25(0.12- \\
0.43)\end{array}$ \\
\hline$\leq 0.25 \mathrm{D}, n(\%)$ & $486(24.3)$ & $700(35.0)$ & $931(46.6)$ & $1,015(50.8)$ \\
\hline$\leq 0.50 \mathrm{D}, n(\%)$ & $1,186(59.3)$ & $1,295(64.8)$ & $1,565(78.3)$ & $1,656(82.8)$ \\
\hline$\leq 0.75 \mathrm{D}, n(\%)$ & $1,625(81.3)$ & $1,666(83.3)$ & $1,874(93.7)$ & $1,928(96.4)$ \\
\hline$>1.00 \mathrm{D}, n(\%)$ & $144(7.2)$ & $94(4.7)$ & $26(1.3)$ & $7(0.4)$ \\
\hline
\end{tabular}

$\mathrm{RAE}=$ predicted residual astigmatism error; $\mathrm{D}=$ diopters

RAE was defined as the vectorial difference between the predicted residual astigmatism using methods $\mathrm{A}, \mathrm{B}, \mathrm{C}$, or D and the actual residual astigmatism.

Magnitude of RAE was defined as the magnitude of cylinder power of RAE

Method A used keratometric astigmatism and the intended incision-induced keratometric astigmatism to predict residual astigmatism

Method B used total corneal astigmatism and the intended incision-induced keratometric astigmatism to predict residual astigmatism

Method C used total corneal astigmatism and both intended incision-induced keratometric and posterior corneal astigmatisms to predict residual astigmatism

Method D used total corneal astigmatism, the intended incision-induced keratometric and posterior corneal astigmatisms, and effective lens position to predict residual 
* Values are median (interquartile range)

The mean vector difference between the actual residual astigmatism (method E) and the predicted residual astigmatism derived using methods $\mathrm{A}, \mathrm{B}, \mathrm{C}$, and D was $0.11 \pm 0.39 @ 180^{\circ}, 0.16 \pm 0.33 @ 91^{\circ}, 0.01 \pm 0.26 @ 71^{\circ}$, and $0.01 \pm 0.24$ (a) $16^{\circ}$ respectively (Fig. 3).

Fig. 3

Double-angle plots of the vector difference between the actual residual astigmatism and the predicted residual astigmatism derived using methods A, B, C, and D. a Method A. b Method B. c Method C. d Method D. Predicting methods are the same as in Table 3

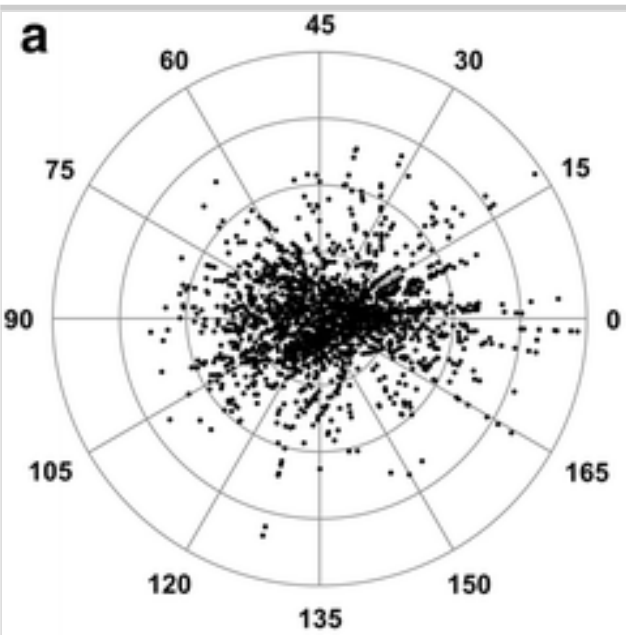

$0.11 \pm 0.39 @ 180^{\circ}$

Each ring $=0.50 \mathrm{D}$, outer ring $=2.00 \mathrm{D}$

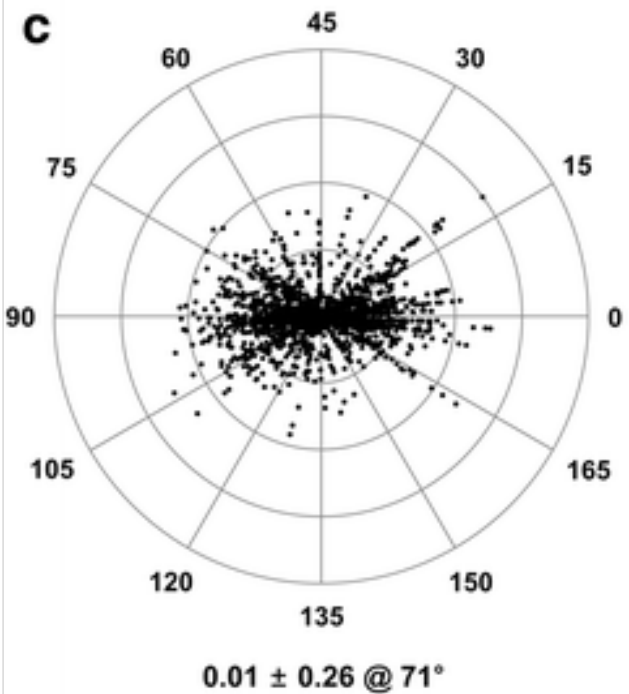

Each ring $=0.50 \mathrm{D}$, outer ring $=2.00 \mathrm{D}$

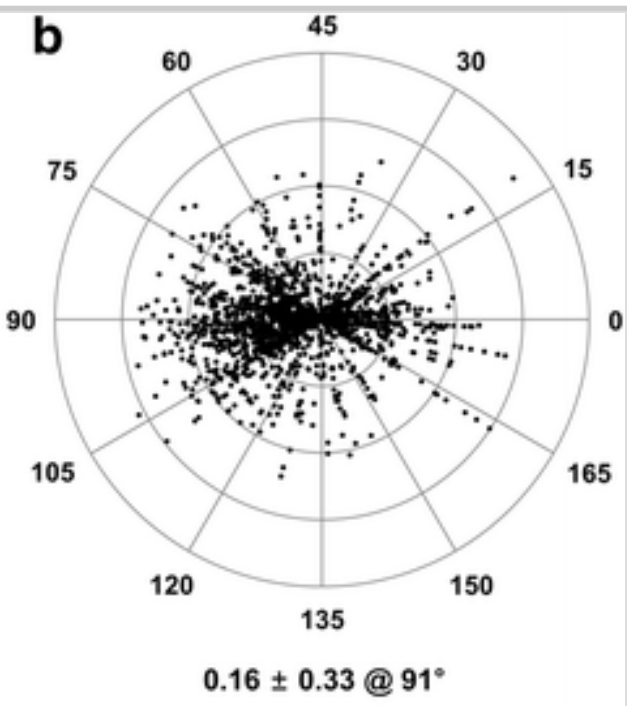

Each ring $=0.50 \mathrm{D}$, outer ring $=2.00 \mathrm{D}$

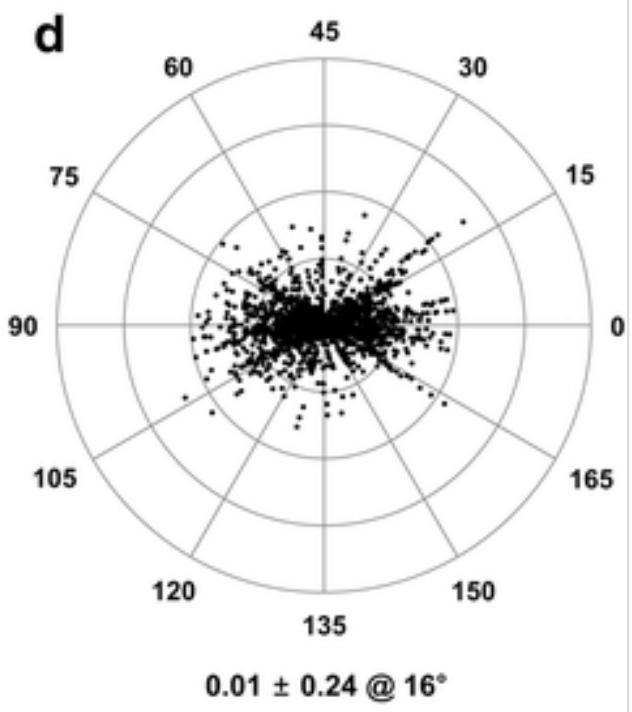

Each ring $=0.50 \mathrm{D}$, outer ring $=2.00 \mathrm{D}$ 
Investigation of the IOL add power calculator for calculating the toric IOL cylinder power and its axis

The toric IOL cylinder power required to fully correct the total corneal astigmatism predicted by the IAPC had an excellent goodness-of-fit with the value predicted by the numerical ray-tracing data $\left(\mathrm{Y}=0.9846 \mathrm{X}-0.1153, R^{2}=\right.$ 0.999; Fig. 4a). There was also an excellent goodness-of-fit between the toric IOL axis needed to fully correct the total corneal astigmatism predicted by the IAPC and that predicted by ray-tracing simulation results $(\mathrm{Y}=0.9998 \mathrm{X}-0.1083$, $R^{2}=1.000$, Fig. 4b).

Fig. 4

Linear regression analysis of the relationship between the toric intraocular lens (IOL) cylinder power and its axis needed to fully correct the total corneal astigmatism predicted by the IOL add power calculator and that predicted by raytracing simulation. a The toric IOL cylinder power. $\mathbf{b}$ The toric IOL axis
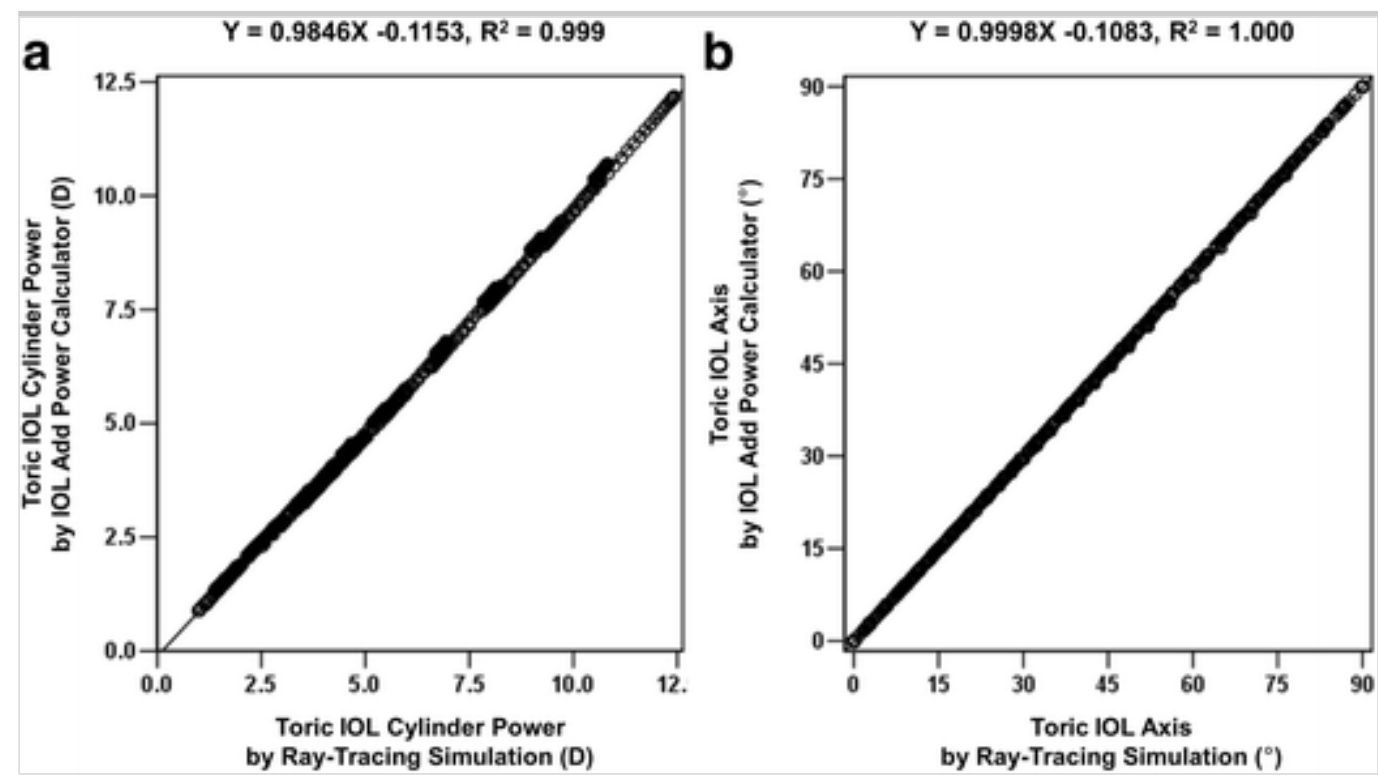

The Bland-Altman plot showed that the difference in predicted toric IOL cylinder power between the IAPC and ray-tracing simulation slightly increased as the mean value of the two methods increased (Fig. 5a). However, in more than $99 \%$ of calculations, the difference in predicted toric IOL cylinder power between the IAPC and ray-tracing simulation was less than $10 \%$ of the mean value of the two methods (Fig. 5a). The difference in predicted toric IOL axis between the IAPC and ray-tracing simulation appeared consistent over the range of toric IOL axes tested. More than $99 \%$ of calculations were within 1 degree of the difference between the IAPC and ray-tracing simulation (Fig. 5b).

Fig. 5

Bland-Altman plot of the toric intraocular lens (IOL) cylinder power and its axis needed to fully correct the total corneal astigmatism predicted by the IOL add 
power calculator and that predicted by ray-tracing simulation. a The toric IOL cylinder power. b The toric IOL axis. Toric IOL cylinder power predicted by the IOL add power calculator showed a bias toward lower values compared with that predicted by ray-tracing simulation, averaging -0.20 diopters (D) $(95 \%$ limits of agreement, -0.03 to $-0.37 \mathrm{D}$ ). The toric IOL axis predicted by the IOL add power calculator showed a bias toward lower values compared with that predicted by raytracing simulation, averaging -0.12 degrees ( $95 \%$ limits of agreement, $=0.23$ to -0.47 degrees). The mean differences and the $95 \%$ confidence limits of the bias are shown as 3 lines
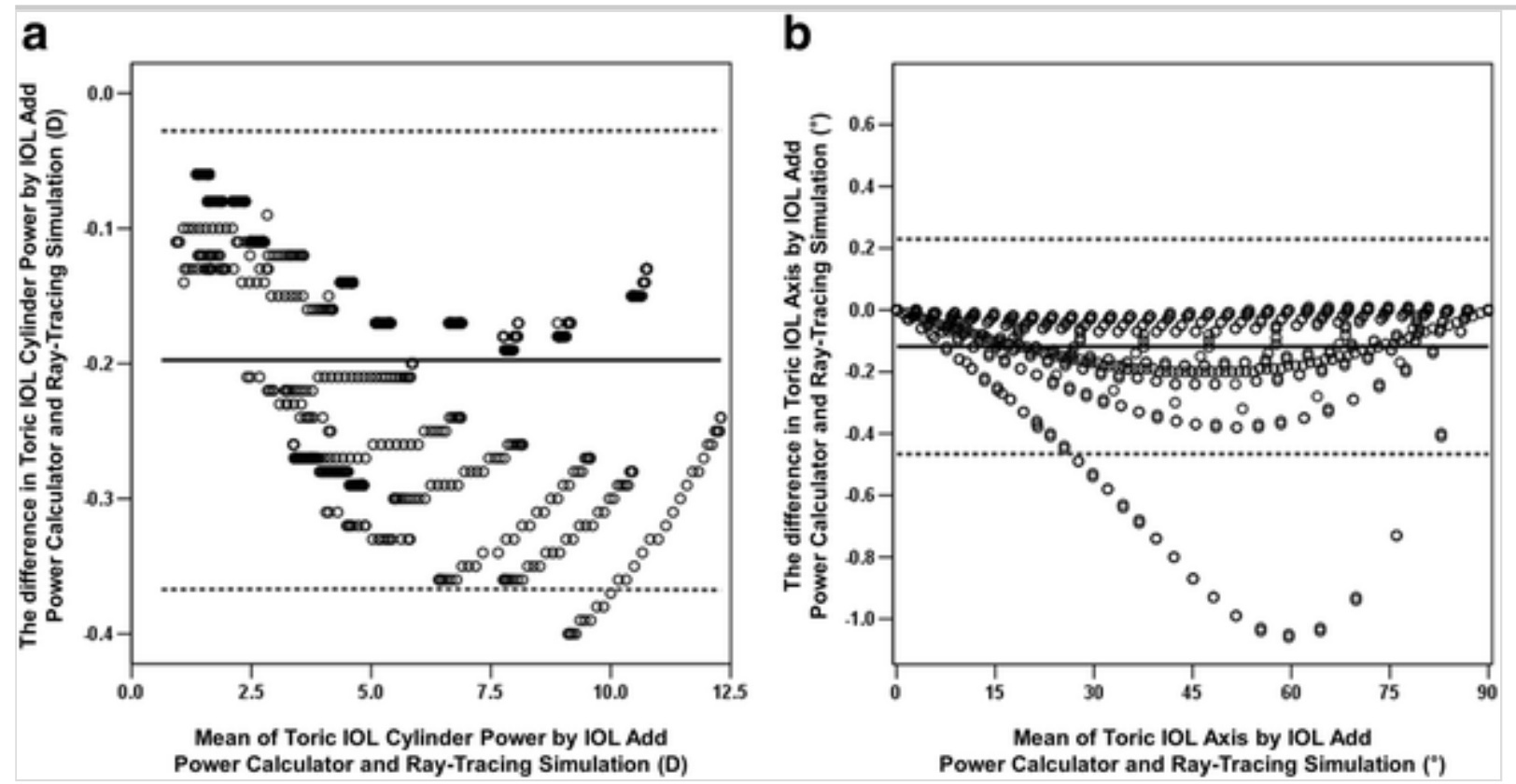

\section{Discussion}

In this study, we introduced the IAPC for predicting residual astigmatism using anterior and posterior corneal radii, incision-induced keratometric and posterior corneal astigmatisms, and ELP. We showed that the toric IOL calculation derived through the IAPC provides a more accurate residual astigmatism prediction than those predicted using methods that neglect one or more of posterior corneal astigmatism, incision-induced posterior corneal astigmatism, and ELP values. When predicting corneal astigmatism correction by toric IOLs, neglecting the posterior corneal astigmatism can lead to errors in the estimation of total corneal astigmatism [ 7,8$]$. Neglecting incision-induced posterior corneal astigmatism can lead to a deviation in the estimation of surgically-induced astigmatism on the cornea $[9,28]$. Inattention to the ELP can lead to an underestimation or overestimation of the corneal plane effective cylinder power of the toric IOL [11 ]. The IAPC used in this study uses posterior corneal astigmatism, incisioninduced posterior corneal astigmatism, and ELP to predict the residual astigmatism and corneal plane effective cylinder power of toric IOLs. There was 
an excellent goodness-of-fit between the IAPC predictions and those using raytracing simulation. The regression coefficient was 0.9846 for toric IOL cylinder power and was 0.9998 for toric IOL axis. These results support the validity of the IAPC in predicting corneal astigmatism correction by toric IOLs.

When incision-induced posterior corneal astigmatism was considered in predicting corneal astigmatism correction by toric IOLs, there was considerable improvement in the accuracy of the estimate of residual astigmatism (Method B vs C). In contrast with the results of this study, a previous study that investigated factors influencing the residual astigmatism after toric IOL implantation showed that considering surgically-induced corneal astigmatism in the toric IOL calculation did not lead to a significant improvement [6]. However, the observed surgically-induced corneal astigmatism in that study was not incision-induced total corneal astigmatism, but rather incision-induced keratometric astigmatism [6]. Although incision-induced keratometric astigmatism has been used by most cataract surgeons in predicting residual astigmatism after cataract surgery with toric IOL, Cheng et al. [28] showed that neglecting incision-induced posterior corneal astigmatism led to an incorrect estimation of incision-induced total corneal astigmatism. In addition, Nemeth et al. [9] also showed that incisioninduced posterior corneal astigmatism can have a significant clinical impact in predicting residual astigmatism after cataract surgery. If the intended incisioninduced posterior corneal astigmatism is obtained using data gathered from an individual surgeon, this can be entered into the IAPC, and the user can then predict a residual astigmatism that considers incision-induced posterior corneal astigmatism.

In this study, it was assumed that the corneal incision was made at the steep meridian of total corneal astigmatism. When an on-axis corneal incision is made, incision-induced keratometric astigmatism reduces the total corneal astigmatism; however, incision-induced posterior corneal astigmatism might counteract the effect of incision-induced keratometric astigmatism. The outcome of the use of on-axis corneal incision or temporal corneal incision might be changed if the amount of incision-induced posterior corneal astigmatism is greater than the amount of incision-induced keratometric astigmatism. A previous study showed that the magnitude of incision-induced posterior corneal astigmatism was $0.5 \mathrm{D}$ or greater in $25 \%$ [9], and the more central location of the inner end of the corneal incision might induce a greater change in the radius in the central portion of the posterior corneal surface [28]. Thus, the reverse situation might also be possible, although the amount of incision-induced keratometric astigmatism was greater than the amount of incision-induced posterior corneal astigmatism in a previous study [9]. The better method between on-axis corneal incision and temporal corneal incision can also vary according to the amounts of incision- 
induced keratometric and posterior corneal astigmatism. A more appropriate corneal incision location can be determined by inputting data into the IAPC used in this study, because the IAPC can calculate changes in total corneal astigmatism considering both incision-induced keratometric and posterior corneal astigmatisms.

The improvement in the accuracy of the estimate of residual astigmatism was statistically significant, but smallest when the ELP was also considered (method C vs D). A previous study comparing the accuracy of the SRK/T and Haigis formulas for predicting corneal astigmatism correction with a toric IOL showed that the difference in the median absolute magnitude of error between the two formulas was significant but small [3]. In the IOL power calculation, modern IOL power calculation formulas provide similarly accurate estimates of refractive outcomes in an eye with an average AL. On the other hand, refractive outcomes become more inaccurate in eyes that deviate from the average AL [29, $30]$. Similarly, the accuracy of estimate of residual astigmatism in eyes with an average ELP might be similar between the method using a fixed ratio of 1.46 for estimating corneal plane effective cylinder power of the toric IOL and a method using ELP estimated from the IOL power calculation formula. On the other hand, the difference in corneal plane effective cylinder power of toric IOLs between the method using a fixed ratio of 1.46 and that using ELP tended to be larger in eyes with small or large ELP $[11,17]$. A previous study demonstrated that the Haigis formula is more accurate than the SRK/T formula in predicting both refractive outcome and corneal astigmatism correction by toric IOLs [3]. The more accurate predictions of refractive outcome lead to better predictions of corneal astigmatism correction by toric IOLs. In specific cases, including eyes with short or long AL, surgeons might prefer to use the SRK/T or Hoffer Q formulas rather than the Haigis formula to calculate the IOL power. In addition, the Haigis formula is not always applicable to all eyes and all clinics. Therefore, the IAPC provides the predicted corneal plane effective cylinder power of toric IOLs and residual astigmatism according to the Haigis, Hoffer Q, and SRK/T formulae.

Calculation of corneal astigmatism change is generally conducted using vector analysis [13-15]. Errors in the prediction of astigmatism change can be explained using the magnitude of error and astigmatism correction index. [11] This study used the median magnitude of the predicted residual astigmatism error, because ophthalmologists are familiar with the median absolute error, which is defined as the median absolute value of the predicted refractive error in IOL power calculation. In previous studies, we introduced the term 'median magnitude of the predicted residual astigmatism error' and showed that this measure is effective for comparing the prediction of corneal astigmatism 
correction by toric IOLs among different methods $[3,12]$.

There are some limitations to the present study. First, it was assumed that the anterior cylinder axis marks of toric IOLs were accurately placed at the steep meridian of the corneal astigmatism. Although previous studies have shown that the toric IOL has good rotational stability, toric IOL axis errors remain an issue $[31,32]$. However, because the aim of this study was to evaluate the accuracy of the predicted residual astigmatism using anterior and posterior corneal radii, incision-induced keratometric and posterior corneal astigmatisms, and ELP through the IAPC, this study did not consider the predicted residual astigmatism error due to toric IOL axis errors. Second, error occurrence is inevitable when using actual biometric measurement data, which can be noisy and incomplete in the IAPC, even though the calculation method was validated with the ray-tracing simulation. In particular, questions have been raised about the accuracy and reliability of the measurement from the Scheimpflug camera, and the prediction of postoperative astigmatism using Scheimpflug keratometry could be improved by alternate methods [33-36]. Thus, the IAPC used in this study should be substantiated in a clinical setting. More accurate biometric measurement data might more accurately predict the amount of corneal astigmatism correction by toric IOLs in the IAPC. Third, this study did not consider variations in the design of the IOLs or the IOL thickness. In the future, a large-scale clinical study that considers IOL design, thickness, and toric IOL axis errors will be needed to improve the accuracy of the IAPC predictions for astigmatism correction by toric IOLs.

In conclusion, the prediction of corneal astigmatism correction with the toric IOL based on anterior and posterior corneal radii, incision-induced keratometric and posterior corneal astigmatisms, and ELP was more accurate than that predicted when one or more of those parameters were not considered. The IAPC used in this study is a simple and accurate method for predicting the toric IOL cylinder power and its axis to correct total corneal astigmatism.

\section{Compliance with ethical standards}

Funding This study was supported in part by the SRC program (20100027910) of the Center for Galaxy Evolution Research (CGER), by the Korea Astronomy and Space Science Institute under the R\&D program (Project No. 2014-9-710-03) supervised by the Ministry of Science, ICT and Future Planning, South Korea, and by the Busan Sungmo Eye Hospital Sodam Scholarship Committee, Busan, South Korea. The sponsor had no role in the design or conduct of this research. 
Conflict of interest All authors certify that they have no affiliations with or involvement in any organization or entity with any financial interest (such as honoraria; educational grants; participation in speakers' bureaus; membership, employment, consultancies, stock ownership, or other equity interest; and expert testimony or patent-licensing arrangements) or non-financial interest (such as personal or professional relationships, affiliations, knowledge, or beliefs) in the subject matter or materials discussed in this manuscript.

Ethical approval All procedures performed in studies involving human participants were in accordance with the ethical standards of the institutional and/or national research committee and with the 1964 Helsinki Declaration and its later amendments or comparable ethical standards. For this type of study, formal consent is not required.

Financial disclosure None.

\section{Electronic supplementary material}

Below is the link to the electronic supplementary material.

\section{ESM 1}

(XLSM $307 \mathrm{~kb})$

\section{References}

1. Visser N, Bauer NJ, Nuijts RM (2013) Toric intraocular lenses: historical overview, patient selection, IOL calculation, surgical techniques, clinical outcomes, and complications. J Cataract Refract Surg 39:624-637

2. Eom Y, Nam KT, Kang SY, Kim HM, Song JS (2013) Axis difference between corneal and internal astigmatism to consider for toric intraocular lenses. Am J Ophthalmol 156:1112-1119

3. Eom Y, Song JS, Kim YY, Kim HM (2015) Comparison of SRK/T and Haigis formulas for predicting corneal astigmatism correction with toric intraocular lenses. J Cataract Refract Surg 41:1650-1657

4. Novis C (2000) Astigmatism and toric intraocular lenses. Curr Opin Ophthalmol 11:47-50

5. Weinand F, Jung A, Stein A, Pfutzner A, Becker R, Pavlovic S (2007) Rotational stability of a single-piece hydrophobic acrylic intraocular lens: 
new method for high-precision rotation control. J Cataract Refract Surg 33:800-803

6. Savini G, Naeser K (2015) An analysis of the factors influencing the residual refractive astigmatism after cataract surgery with toric intraocular lenses. Invest Ophthalmol Vis Sci 56:827-835

7. Koch DD, Ali SF, Weikert MP, Shirayama M, Jenkins R, Wang L (2012) Contribution of posterior corneal astigmatism to total corneal astigmatism. J Cataract Refract Surg 38:2080-2087

8. Eom Y, Kang SY, Kim HM, Song JS (2014) The effect of posterior corneal flat meridian and astigmatism amount on the total corneal astigmatism estimated from anterior corneal measurements. Graefes Arch Clin Exp Ophthalmol 252:1769-1777

9. Nemeth G, Berta A, Szalai E, Hassan Z, Modis L Jr (2014) Analysis of surgically induced astigmatism on the posterior surface of the cornea. $\mathrm{J}$ Refract Surg 30:604-608

10. Goggin M, Moore S, Esterman A (2011) Outcome of toric intraocular lens implantation after adjusting for anterior chamber depth and intraocular lens sphere equivalent power effects. Arch Ophthalmol 129:998-1003

11. Eom Y, Kang SY, Song JS, Kim YY, Kim HM (2015) Effect of effective lens position on cylinder power of toric intraocular lenses. Can J Ophthalmol $50: 26-32$

12. Eom Y, Rhim JW, Kang SY, Kim SW, Song JS, Kim HM (2015) Toric intraocular lens calculations using ratio of anterior to posterior corneal cylinder power. Am J Ophthalmol 160:717-724, e712

13. Alpins NA (1997) New method of targeting vectors to treat astigmatism. J Cataract Refract Surg 23:65-75

14. Alpins N (2001) Astigmatism analysis by the Alpins method. J Cataract Refract Surg 27:31-49

15. Naeser K (2008) Assessment and statistics of surgically induced astigmatism. Acta Ophthalmol 86(Suppl 1):5-28

16. Olsen T (2007) Calculation of intraocular lens power: a review. Acta 
17. Savini G, Hoffer KJ, Carbonelli M, Ducoli P, Barboni P (2013) Influence of axial length and corneal power on the astigmatic power of toric intraocular lenses. J Cataract Refract Surg 39:1900-1903

18. Holladay JT (1993) Refractive power calculations for intraocular lenses in the phakic eye. Am J Ophthalmol 116:63-66

19. Holladay JT (1997) Standardizing constants for ultrasonic biometry, keratometry, and intraocular lens power calculations. J Cataract Refract Surg 23:1356-1370

20. Haigis W (2004) The Haigis formula. In: Shammas HJ (ed) Intraocular lens power calculations. Slack, Thorofare, NJ, pp 41-57

21. Hoffer KJ (1993) The Hoffer Q formula: a comparison of theoretic and regression formulas. J Cataract Refract Surg 19:700-712

22. Zuberbuhler B, Morrell AJ (2007) Errata in printed Hoffer Q formula. J Cataract Refract Surg 33(2):2, author reply 2-3

23. Retzlaff JA, Sanders DR, Kraff MC (1990) Development of the SRK/T intraocular lens implant power calculation formula. J Cataract Refract Surg $16: 333-340$

24. Haigis W (1993) Occurrence of erroneous anterior chamber depth in the SRK/T formula. J Cataract Refract Surg 19:442-446

25. Eom Y, Song JS, Kim HM (2016) Spectacle plane add power of the multifocal intraocular lenses according to effective lens position. Can J Ophthalmol [Article in Press]

26. Greivenkamp JE, Schwiegerling J, Miller JM, Mellinger MD (1995) Visual acuity modeling using optical raytracing of schematic eyes. Am J Ophthalmol 120:227-240

27. DeHoog E, Doraiswamy A (2014) Evaluation of the impact of light scatter from glistenings in pseudophakic eyes. J Cataract Refract Surg 40:95103

28. Cheng LS, Tsai CY, Tsai RJ, Liou SW, Ho JD (2011) Estimation accuracy 
of surgically induced astigmatism on the cornea when neglecting the posterior corneal surface measurement. Acta Ophthalmol 89:417-422

29. Eom Y, Kang SY, Song JS, Kim YY, Kim HM (2014) Comparison of Hoffer Q and Haigis formulae for intraocular lens power calculation according to the anterior chamber depth in short eyes. Am J Ophthalmol $157: 818-824$, e 812

30. Olsen T, Thim K, Corydon L (1991) Accuracy of the newer generation intraocular lens power calculation formulas in long and short eyes. J Cataract Refract Surg 17:187-193

31. Waltz KL, Featherstone K, Tsai L, Trentacost D (2014) Clinical outcomes of TECNIS toric intraocular lens implantation after cataract removal in patients with corneal astigmatism. Ophthalmology 122:39-47

32. Hirnschall N, Maedel S, Weber M, Findl O (2014) Rotational stability of a single-piece toric acrylic intraocular lens: a pilot study. Am J Ophthalmol 157:405-411, e401

33. Visser N, Berendschot TT, Verbakel F, de Brabander J, Nuijts RM (2012) Comparability and repeatability of corneal astigmatism measurements using different measurement technologies. J Cataract Refract Surg 38:1764-1770

34. Yong Park C, Do JR, Chuck RS (2012) Predicting postoperative astigmatism using Scheimpflug keratometry (Pentacam) and automated keratometry (IOLMaster). Curr Eye Res 37:1091-1098

35. Abulafia A, Hill WE, Franchina M, Barrett GD (2015) Comparison of methods to predict residual astigmatism after intraocular lens implantation. $\mathrm{J}$ Refract Surg 31:699-707

36. Tejedor J, Guirao A (2013) Agreement between refractive and corneal astigmatism in pseudophakic eyes. Cornea 32:783-790 